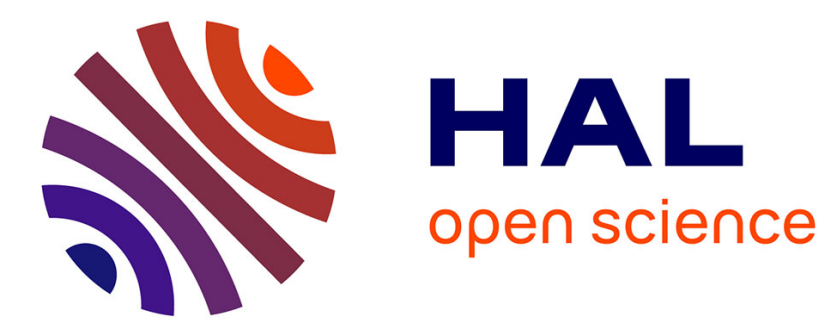

\title{
Failure mode analysis on thermally aged hydrophobic coatings applied to electro wetting
}

Gwenaël Bonfante, Mathieu Maillard, Stéphanie Chevalliot, Benjamin Burger, Bruno Berge, Corinne Gablin, Didier Léonard, Bérangère Toury

\section{- To cite this version:}

Gwenaël Bonfante, Mathieu Maillard, Stéphanie Chevalliot, Benjamin Burger, Bruno Berge, et al.. Failure mode analysis on thermally aged hydrophobic coatings applied to electro wetting. Thin Solid Films, 2018, 646, pp.53 - 60. 10.1016/j.tsf.2017.11.034 . hal-01692363

\section{HAL Id: hal-01692363 https://hal.science/hal-01692363}

Submitted on 13 Apr 2021

HAL is a multi-disciplinary open access archive for the deposit and dissemination of scientific research documents, whether they are published or not. The documents may come from teaching and research institutions in France or abroad, or from public or private research centers.
L'archive ouverte pluridisciplinaire HAL, est destinée au dépôt et à la diffusion de documents scientifiques de niveau recherche, publiés ou non, émanant des établissements d'enseignement et de recherche français ou étrangers, des laboratoires publics ou privés. 


\title{
Failure mode analysis on thermally aged hydrophobic coatings applied to electro wetting
}

Gwenaël BONFANTEab, Mathieu MAILLARDa, Stéphanie CHEVALLIOT ${ }^{\mathrm{b}}$, Benjamin BURGER ${ }^{\mathrm{b}}$, Bruno BERGE ${ }^{\mathrm{b}}$, Corine GABLINc ${ }^{c}$ Léonard DIDIERc, Bérangère TOURYa.

a Université de Lyon, Laboratoire des Multimatériaux et Interfaces, UMR 5615, CNRS-Université Lyon 143 bd du 11 Novembre 1918, F-69622 Villeurbanne, France.

b Varioptic, Parrot SA Bâtiment Tony Garnier, 24 rue Jean Baldassini, 69007 Lyon, France.

c Institut des sciences analytiques, 5 Rue de la Doua, 69100 Villeurbanne, France.

\begin{abstract}
The aim of this study is to investigate the degradation of hydrophobic coatings at the origin of reliability failure. Various properties such as adhesion and wetting after thermal ageing have been investigated. The layers studied, parylene C, Cytop and Fluoropel deposited on silicon wafers are widely used in electrowetting, MEMS and Labon-chip devices. A detailed failure mode analysis is presented, involving chemical surface modification through secondary ion mass spectroscopy by time of flight, X-ray photoelectron spectroscopy, surface energy and tensile strength measurements. We've been able to identify and quantify the origin of failure for each type of coating and the method we applied can be extrapolated to other hydrophobic coating as a benchmark for reliability improvement.
\end{abstract}

\section{Introduction}

Adhesion and durability of coatings on substrates is a major issue in many fields such as painting, adhesive, or wear protection. Understanding the way coatings bond with surfaces remains the more straightforward manner to study rupture mechanisms and long term reliability. For this reason durability of polymer adhesive on different substrates such as ceramic or metals has been studied [1-4]. Improvement from adhesive bonding combined with proper characterization methods prove to be the way to increase durability of adhesive bond, between polymer and metals for example [1]. More specifically, Comrie et al. demonstrated the impact of moisture associated with heat treatment on adhesive joint and the evolution of reliability [2] using a non-destructive method to study and characterize the evolution of joint in a very humid environment. Other improvement on adhesion of paint on plastics involve the composition [5], or the adhesion enhancement (plasma, flame treatment or coupling agents) [6-8]. Garbassi et al. for example, shows the impact of flame treatment on the top surface chemistry and the depth of oxidation for polypropylene pieces. The treated surface is then studied by XPS, TOF-SIMS and contact angle. After several flame treatment, adhesion is promoted thanks to the creation of hydroxyl group on polypropylene pieces surface; and oxidation is shown by apparition of carboxyl group [8].

Electrowetting on dielectric [9] actuation is now widely used for lab-on-chip [10-12], display $[9,13]$, or liquid lenses $[14,15]$ and is based on modulation of wetting properties of electrolyte droplets on surfaces thanks to an electric polarization. It results from the equilibrium of two forces: electrostatic force, which tend to spread electrolyte droplet and surface tension force which tends to limit the expansion of the liquid interface. Even though electrowetting actuation is now available in actual products, many parts of the phenomena remain unknown and need further research since any non-controlled properties modification could lead to device breakdown or dysfunction.

Ageing/breakdown of layers used in electrowetting for instance has been mostly studied when voltage is applied (DC or AC) [15]. Dhindsa et al., studied the self-healing properties of an oxide layer to prevent and repair breakdown [16]. Gupta et al. showed the performance loss of layers by pinning the triple contact line [17]. Optimal thickness used in electrowetting on dielectric (EWOD) correlated with hysteresis is investigated by Chae et al. [18]. In addition to operating conditions, product lifetime is also critical for market acceptance and it is important to evaluate thermal ageing while not in use. Indeed, it is very important to get devices lasting for a very longtime both in use and idle.

In this paper, layers commonly used in electrowetting such as Parylene C, Fluoropel and Cytop are thermally aged in water for seven days at $85{ }^{\circ} \mathrm{C}$, to simulate accelerated ageing while stocking. Strong modifications from such treatment are described through surface modification including chemical 
modification and de-cohesion of layer to identify failure mode for these coatings and improvement strategies.

\section{Experimental details 2.1. Sample preparation}

Parylene $C$ coatings have been prepared on silica substrate by CVD using a Kisco system. The Dichloro-di-para-xylylene cyclic dimer precursor has been provided by Kisco as diX C. Cytop® CTX 809 has been supplied by AGC Chemicals. Hydrophobic coatings based on fluorinated polymers have been obtained by spin coating of a solution of Cytop $®$ directly spun on the latter dielectric coatings of Parylene $\mathrm{C}$ at $4000 \mathrm{rpm}$ for $90 \mathrm{~s}$, Fluoropel ${ }^{\circledR} 1601 \mathrm{~V}$ has been supplied by Cytonix Co. The asreceived product has been spun at $6000 \mathrm{rpm}$ on dielectric coatings of Parylene C. Samples are then annealed at $90{ }^{\circ} \mathrm{C}$ for $>15 \mathrm{~h}$ on a hot plate. Three types of samples are studied: pristine Parylene $\mathrm{C}$ substrate, a Fluoropel covered Parylene $C$ and Cytop covered Parylene C. Parylene $C$ coating is $5.6 \mu \mathrm{m}$ thick and additional layer of Cytop and Fluoropel are about $50 \mathrm{~nm}$ thick (see Table 1).

Table 1. Thickness and capacitance of layers studied in electrowetting.

\begin{tabular}{|c|c|c|c|c|c|}
\hline & \multicolumn{2}{|c|}{ Insulating layer } & \multicolumn{2}{|c|}{ Hydrophobic coating } & \multirow{2}{*}{$\begin{array}{l}\text { Capacitance } \\
\mathrm{Cs}\left(\mathrm{F} / \mathrm{m}^{2}\right)\end{array}$} \\
\hline & $\mathrm{d}(\mathrm{nm})$ & $\varepsilon$ & $\mathrm{d}(\mathrm{nm})$ & $\varepsilon$ & \\
\hline Parylene C & 5600 & 3.1 & - & - & $4.9 \mathrm{E}-06$ \\
\hline $\begin{array}{c}\text { Fluoropel covered } \\
\text { parylene C }\end{array}$ & 5600 & 3.1 & 50 & 2.1 & $4.8 \mathrm{E}-06$ \\
\hline $\begin{array}{l}\text { Cytop covered } \\
\text { parylene C }\end{array}$ & 5600 & 3.1 & 50 & 2.1 & $4.8 \mathrm{E}-06$ \\
\hline
\end{tabular}

\subsection{Ageing procedure}

A hermetic sample holder, with a capacity of 12 cells, permits to age any surfaces in any liquid. In our case, we used de-ionized water as we previously established (internal work within Varioptic) that it was critical for both hydrophobic properties and adhesion of the layer studied. In order to have a reproducible ageing procedure, we also used a standardized treatment [19], storing samples for one week at $85{ }^{\circ} \mathrm{C}$ in $10 \%$ of relative humidity in a controlled conditions Binder oven. This ageing procedure is described in IEC 60068-2-2 norm.

\subsection{Surface energy}

The theory behind these methods (one liquid OWKR and two liquids) are used as described by Maillard et al. [20]. Contact angles have been measured on a Kruss easydrop® goniometer associated to the software Drop Shape Analysis using water [21], decane [22], octane [22], diodomethane [23], ethylene glycol [24,25], and bromonaphtalene [24] as reference liquids. Different coatings have been used such as Parylene C coatings 19 covered or not with fluorinated coatings of Cytop and Fluoropel. Each surface is tested with at least three different liquids for reproducibility. For each tested liquid, three drops of $3 \mu \mathrm{L}$ are deposited onto the surface, measuring the advancing contact angle in an ambient medium (air or electrolyte). Since substrates are made of $\langle 100\rangle$ silicon wafer, surface roughness is extremely low (ra < $1 \mathrm{~nm}$ ) and deposition method for Parylene $\mathrm{C}$ and top-coats does not significantly increase roughness $[26,27]$.

\subsection{Adhesion}

A modified tension-compression machine has been used to test adhesion of samples. Customized pulling test pieces have been made: the section for testing is of about $2.2 \mathrm{~cm}^{2}$. Then, the different parts of the system are glued with epoxy-amine (Araldite 90s) on the coating side and cyanoacrylate glue (Loctite Superglue 3) on the substrate. Each side of the samples are spread with the corresponding glue, hold for $30 \mathrm{~s}$ and finally let to dry overnight. The testing area is delimited by cutting the coating around the pulling test-piece in order to control the de-adhesion surface. Thanks to a software coupled to the machine, the strength leading to the surface break is given and adhesion can be appreciated with the equation: $\mathrm{C}=\mathrm{F} / \mathrm{S}$ with $\mathrm{C}$ the constraint in Pascal, $\mathrm{F}$ the force in Newton and $\mathrm{S}$ the surface in square meters. 
Each coating has been tested at least 5 times to be representative and reproducible.

Afterwards, the rupture zone is observed with Scanning Electron Microscopy (SEM) and analyzed by energy-dispersive X-ray spectroscopy (EDS) in order to characterize species remaining on the samples and establish failure mode.

\subsection{Scanning electron microscopy (SEM)}

The SEM used is the FEI Quanta 250 FEG allowing us to take pictures between 1 and $10 \mathrm{kV}$ at around 400× magnitude under high vacuum. Each sample were fixed using carbon scotch on sample holder. Parylene $\mathrm{C}$ coatings have been metalized with platinum on a Balzers MED 010. Fluoropel and Cytop coatings were not metalized because of their low thickness $(\leq 25 \mathrm{~nm})$, in order to avoid roughness and surface aspect artifacts.

\subsection{XPS and TOF-SIMS}

Measurements were done using a PHI Quantera SXM instrument (Physical Electronics, Chanhassen, USA) equipped with a 180 hemispherical electron energy analyzer and a monochromatized $\mathrm{Al} \mathrm{K}_{c}(1486.6 \mathrm{eV})$ source operated at $15 \mathrm{kV}$ and $4 \mathrm{~mA}$. The analysis spot had a diameter of $200 \mu \mathrm{m}$ and the detection angle relative to the substrate surface was $45^{\circ}$. Standard deviations were calculated from measurements performed on two different areas. Data were analyzed using the Multipak software. The depth probed of XPS analysis is between 5 and $10 \mathrm{~nm}$. Time-of-Flight Secondary Ion Mass Spectrometry (ToF-SIMS) measurements were carried out on a TRIFT III ToF-SIMS instrument from Physical Electronics operated with a pulsed $22 \mathrm{keV} \mathrm{Au}{ }^{+}$ion gun (ion current of $2 \mathrm{nA}$ ) rastered over a $300 \mu \mathrm{m} \times 300 \mu \mathrm{m}$ area. An electron gun was operated in pulsed mode at low electron energy for charge compensation. Ion dose was kept below the static conditions limit. Data were analyzed using the WinCadence software. Mass calibration was performed on hydrocarbon and fluorocarbon secondary ions. The coatings were analyzed on $<3 \mathrm{~nm}$ of depth and under ultra-vacuum.

\section{Results and discussion 3.1. Failure test: EWOD}

A simple way to see whether or not a layer is aged, is to perform an electrowetting test. Electrowetting corresponds to the modification of wetting properties, from an electrolyte fluid standing on an electrically polarized dielectric coating and it results from the equilibrium of interfacial energy between the spreading electrolyte on a surface and electrostatic energy condensing ions from electrolyte solution near the contact line. Phenomenon occurs whether medium surround electrolyte is air or any non-conducting fluid such as oil and is well described by Young-Lippmann Eq. (1):

$$
\cos \theta(V)=\cos \theta_{0}-\frac{1}{2} \frac{\varepsilon \varepsilon_{0}}{e \gamma_{L G}} V^{2}
$$

where $\theta$ is the contact angle from the non-conductive medium at a given voltage, $\theta 0$ the natural contact angle, $\varepsilon$ the permittivity of the material and $\varepsilon 0$ the vacuum permittivity, e is the dielectric thickness, $\mathrm{V}$ is the applied voltage and $\gamma \mathrm{LG}$ is the interfacial tension between the drop and the medium (usually around $15 \mathrm{~mJ} / \mathrm{m} 2$ with the liquids used)

The theory describing such phenomenon is well explained by Berge et al. [28]

Weathering leads to surface modifications of the layers (hydrolysis, roughness modification, decohesion), leading to hysteresis of voltage [29-31]. In optical devices, accuracy and repeatability is essential, and phenomena like hysteresis must be avoided to remain reproducible and reliable over extensive use.

Fig. 1 describes the effect of ageing on three layers: Parylene C, Fluoropel and Cytop new samples, show almost no hysteresis $\left(\Delta \theta<5^{\circ}\right)$. On the other hand, aged layers, on the right side of Fig. 1 , show two modifications of the electro-wetting behavior. The most noticeable is the increase from starting angle demonstrating a modification of the film surface. Then, hysteresis is very clear on each sample: for a same voltage, raising and dropping angles induce variable contact angle. More precisely for Fluoropel, the behavior's evolution shows a slighter hysteresis. Of course hysteresis here is a major issue for applications, in liquid lens focus strategy for instance, such hysteresis would induce a noticeable focal length difference for the exact same voltage depending on the voltage way of variation. Table 2 presents the hysteresis for each layer studied after ageing. 

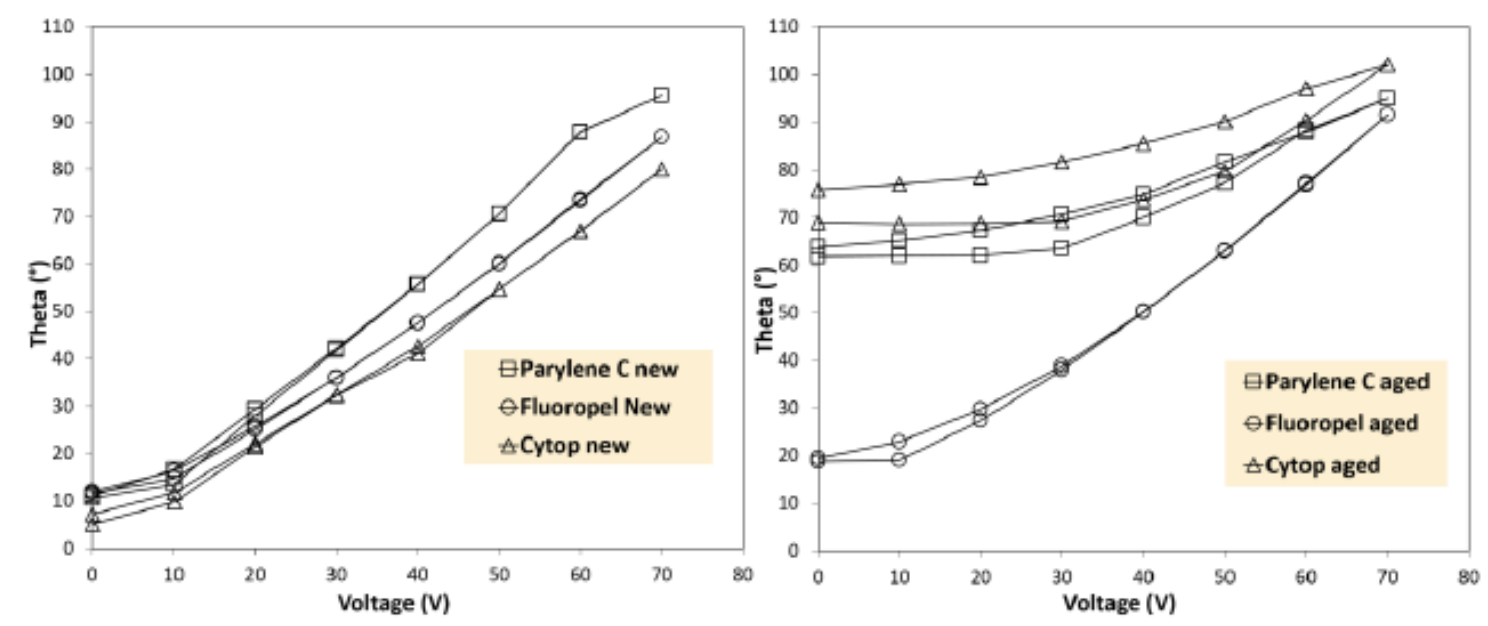

Figure 1 - EWOD for Parylene C (square), Fluoropel (circle) and Cytop (triangle) showing the contact angle as a function of the voltage ( $1 \mathrm{kHz}$ frequence, in liquids specially designed by Varioptic) before (left) and after (right) thermal ageing.

Table 2. Hysteresis after ageing in degree and its correspondence in diopters.

\begin{tabular}{llll} 
Layer & Parylene C & Fluoropel & Cytop \\
\hline Hysteresis ( ${ }^{\circ}$ ) & 7 & 2 & 10 \\
Hysteresis ( $)$ for a liquid lens & 12.25 & 3.5 & 17.5
\end{tabular}

\subsection{Failure mode analysis}

Analysis of the failure mode is based on different characterizations such as coating adhesion, surface morphology, and chemical properties. Indeed, hysteresis is directly linked to modification in the surface properties (morphologically and chemically) induced by ageing the layers. Alteration of such thin films creates anchor points, generating potential barrier for the drop spreading leading to differences on contact angle depending on the path taken. Two hypothesis lead to the formation of these anchor points: loose area or fold generated by decohesion of the underneath layer, creating a pocket in-between layers; direct chemical modification of the top layer, creating polar groups such as hydroxyl groups which are hydrophilic. In order to identify the origin of hysteresis we fully characterize modifications from coatings induced by thermal ageing. The surface energy measurement, using one or two liquids [20], gives a direct estimate of the surface modification by measuring variations in the surface energy polar part. If no change is revealed, adhesion test provide further information when coupled with scanning electron microscopy (SEM) analysis. Finally, in order to fully characterize the top layer (oxidation, hydrophylisation, degradation...), Time-of-Flight Secondary Ion Mass Spectrometry (TOF-SIMS) and X-ray Photoelectron Spectroscopy characterizations analysis are performed.

Surface energy measurements give a very good appreciation of the coating's deterioration by showing increasing of the polar component. Theory behind the calculation is given by the literature [20].

Polar contribution to surface energy from all tested layers are presented in Fig. 2 and exhibit variations. The Fluoropel layer presents the less variation from $0.004 \pm 0.005 \mathrm{~mJ} / \mathrm{m}^{2}$ to $0.01 \pm 0.02 \mathrm{~mJ} / \mathrm{m}^{2}$, however, relative error for both measurements makes them irrelevant. In fact, polar parts for fluoropolymer are too low to be precisely measured and remain unchanged by thermal ageing. The polar part increase on Cytop sample is more noticeable. Indeed, the polar part goes from $0.005 \pm 0.001 \mathrm{~mJ} / \mathrm{m}^{2}$ to $0.4 \pm 0.02 \mathrm{~mJ} / \mathrm{m}^{2}$. Finally, the increase for Parylene C is shown on Fig. 2. The polar part goes from $0.1 \pm$ $0.002 \mathrm{~mJ} / \mathrm{m}^{2}$ to $2.5 \pm 0.04 \mathrm{~mJ} / \mathrm{m}^{2}$. Even if, generally speaking, fluoropolymer layers are more resilient to age and weakly interact with their environment, ageing seems to affects samples with some variations. As shown on Fig. 2, all the layers analyzed have initially a low polar part $\left(<0.2 \mathrm{~mJ} / \mathrm{m}^{2}\right)$ but surface polar parts always increase after ageing, showing an alteration of the top layer. Parylene $\mathrm{C}$ and Cytop polar part 
increase readily explain differences observed during the EWOD measurements since ageing could create hydroxyls termination at the coating interface with liquid phase. Now increasing the polar components has a drastic effect on increasing initial contact angle and hysteresis consequently [31]. However, Fluoropel hysteresis and starting angle modifications could not be explained from the insignificant variation of the polar part. Two hypothesis arise: de-cohesion of Fluoropel layer from its under-layer (Parylene C) or a top layer's chemical modification not visible through surface energy measurements.

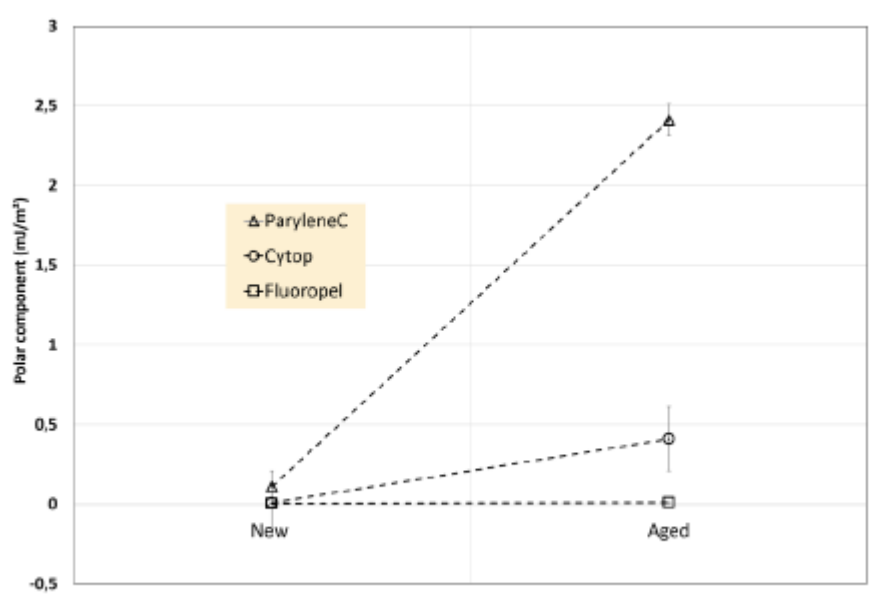

Figure 2 - Polar part modification measured with the two liquids method before and after ageing in water for seven days at $85^{\circ} \mathrm{C}$ in $10 \%$ humidity for Parylene C (triangle), Cytop (circle) and Fluoropel (square).

Surface energy measurement is usually a good method to probe macroscopically the top surface modifications. However, in the case of Fluoropel, the low polarity criteria proved to be necessary but not sufficient and a deeper analysis is required to understand the ageing process. De-cohesion is investigated thanks to adhesion test coupled with SEM whereas TOF-SIMS, one of the most suitable method to investigate the very top surface, is used to understand the chemical evolution of samples.

\subsection{Adhesion}

The other hypothesis linked to ageing is layer de-cohesion, between or within layers. In order to investigate layer ruptures, adhesion test, especially pull-off test, are performed coupled by SEM and EDS analysis.

Table 3 presents the de-adhesion forces and works for the different layers studied before and after weathering. Film rupture is occurring on/within the top surface, leading to a circular area which can be easily observed by SEM to identify rupture face and breaking mode. As presented in Fig. 3, break occurs, for the layer tested, around $300 \mathrm{~N}$ at an elongation of $0.25 \mathrm{~mm}$. The force is then divided by the surface area tested to give a constraint in Pascal $(\mathrm{Pa})$ and a total de-adhesion work of about $\mathrm{W}=480 \mathrm{~J} / \mathrm{m}^{2}$.

Table 3. Experimental data for adhesion testing before and after ageing on Fluoropel, Cytop and Parylene C.

\begin{tabular}{|c|c|c|c|c|c|c|}
\hline & \multicolumn{2}{|c|}{ Fluoropel - Parylene C } & \multicolumn{2}{|c|}{ Cytop - Parylene C } & \multicolumn{2}{|c|}{ Parylene C } \\
\hline & New & Aged & New & Aged & New & Aged \\
\hline Constrain $(\mathrm{Pa})$ & 1.3 MPa & $4 \mathrm{MPa}$ & $13.2 \mathrm{MPa}$ & $5 \mathrm{MPa}$ & $15.3 \mathrm{MPa}$ & $11.5 \mathrm{MPa}$ \\
\hline Adhesion $\left(\mathrm{J} / \mathrm{m}^{2}\right)$ & 715 & 214 & 650 & 91 & 974 & 780 \\
\hline Uncertainty & 390 & 103 & 364 & 48 & 66 & 285 \\
\hline
\end{tabular}




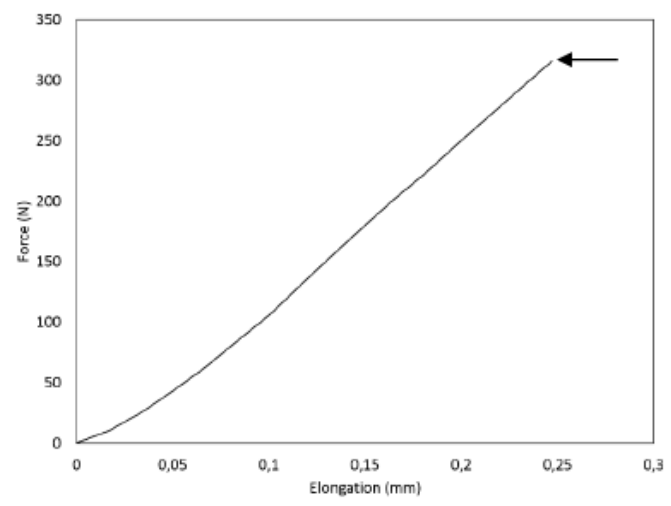

Figure 3 - Typical Curve obtained from an adhesion test on a layer. Breaking point (arrow) is observed around 320 newton, correspond to de-adhesion work of roughly $260 \mathrm{~J} / \mathrm{m}^{2}$.

Fluoropel cohesion is divided by three after ageing coming from $700 \mathrm{~J} / \mathrm{m}^{2}$ to $200 \mathrm{~J} / \mathrm{m}^{2}$. Cytop adhesion work comes from $650 \mathrm{~J} / \mathrm{m}^{2}$ to $91 \mathrm{~J} / \mathrm{m}^{2}$ after ageing. Parylene is only lightly alterated by ageing, decreasing from $974 \mathrm{~J} / \mathrm{m}^{2}$ to $780 \mathrm{~J} / \mathrm{m}^{2}$. The wide uncertainty is due to difficulty to normalize the preparation of samples.

Fig. 4 shows two pictures of pulled off Parylene C layers new (left) and aged (right) taken by SEM. For both samples, there is delamination of the top layer leading, to a complete de-adhesion of Parylene $\mathrm{C}$ from the silicon wafer. To better appreciate the quantity of layer removed, EDS has been performed on dark grey area (remaining part of the top layer) and light grey area (partial or complete removal). The left EDS spectrums correspond to the non-aged surface of Parylene C. The top left one is linked to dark area, bottom left is the spectrum for light grey area. Chlorine and carbon peaks are linked to chlorinated polymer Parylene $\mathrm{C}\left(\mathrm{C}_{8} \mathrm{H}_{7} \mathrm{Cl}\right)$ and silicon peak corresponds to the wafer underneath. Before pull-off test, only Parylene $\mathrm{C}$ is visible by the EDS detector. Removed area shows silicon peak with Parylene C's peaks: a part of the layer is pulled decreasing the thickness of the remaining layer.
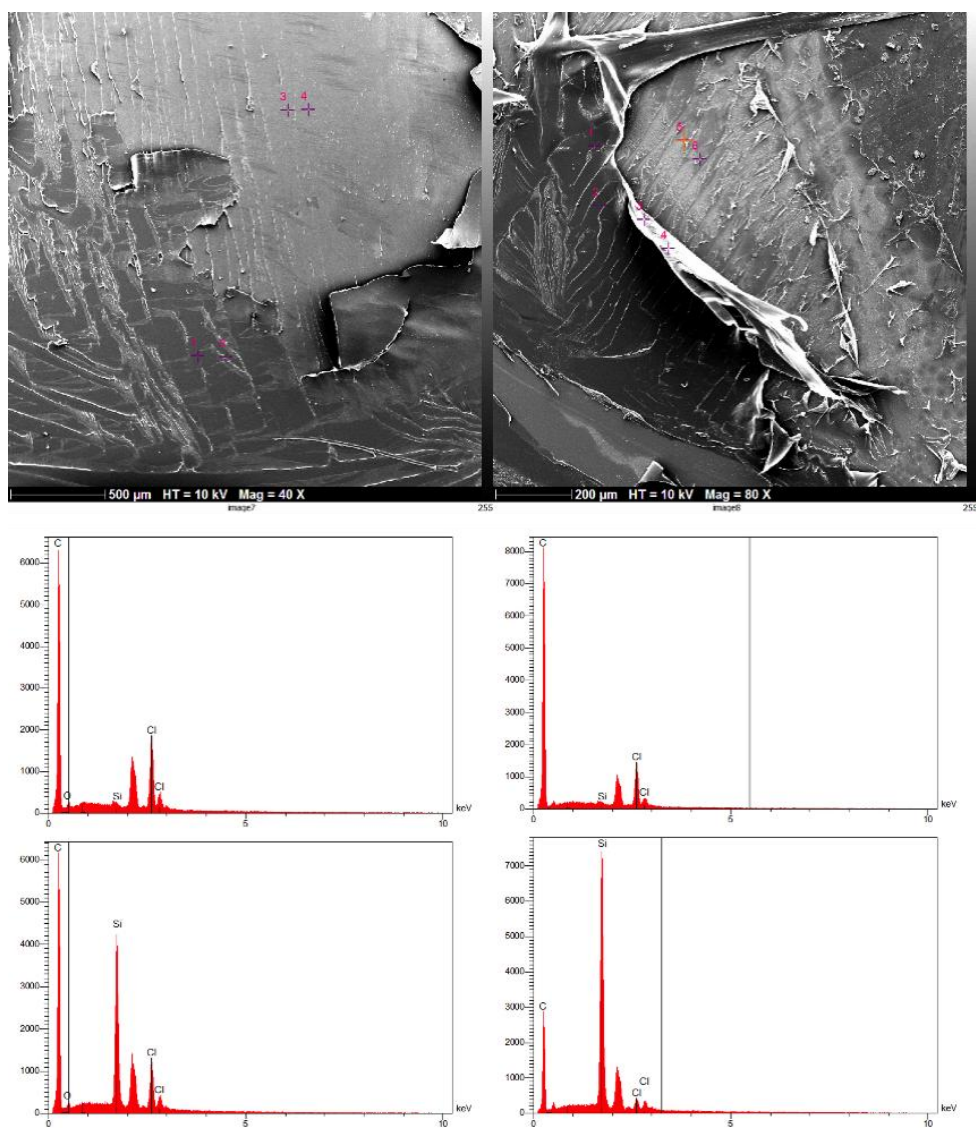
Figure 4 - SEM pictures of new (left) and aged (right) Parylene $C$ samples and coupled EDS analysis on remaining layer (top) and pulled off (down).

Aged samples exhibit similar delamination than new samples. EDS analysis exhibits similar peaks, however, chlorine and carbon peaks intensity are drastically reduced: layer is almost completely removed after adhesion test. Ageing slightly weakened the Parylene $\mathrm{C}$ interface, as demonstrated by SEM EDS analysis.

Unfortunately Fluoropel being very thin and sensible to charging effect under electron beam, pictures and image analysis were not straightforward and we could only compare in a qualitative way the differences between new and aged samples after adhesion test.

No real layer's alteration could be noted on Fluoropel: ageing effects on layers' cohesion is visible only by adhesion test. The work needed to pull out is divided by two after weathering. However, the effect is not clearly obvious by SEM clichés (charging effect).

On the other hand, Cytop does not charge under electron beam leading to pictures but no EDS data were gathered because of lack of significant signal. Fig. 5 presents Cytop SEM pictures of a new layer and an aged layer after adhesion test.

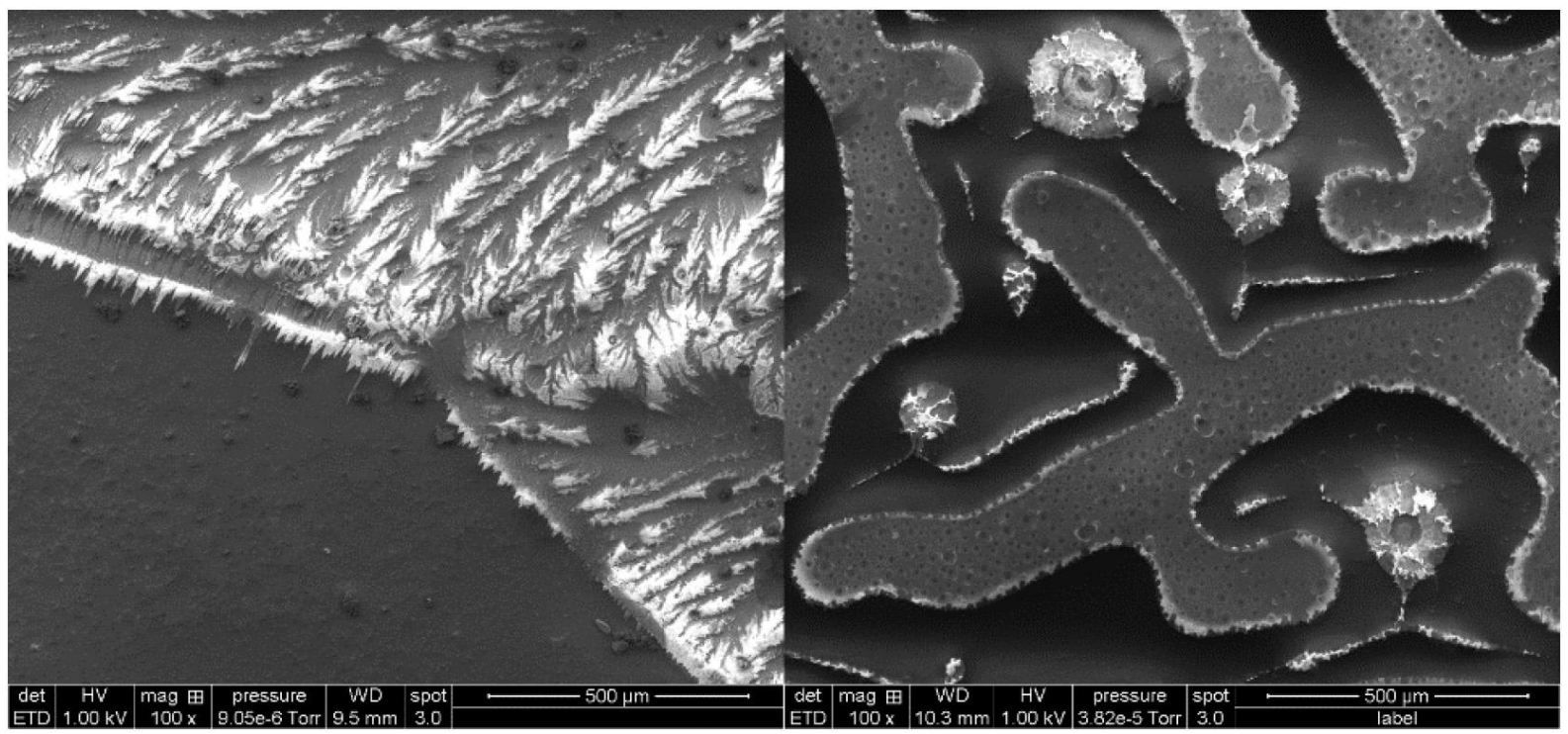

Figure 5 - SEM pictures of new (left) and aged (right) Cytop samples.

After ageing and adhesion test, Cytop layer forms patterns. The main hypothesis is that water diffuse through fluorinated layer and condensate or weaken the interface between polymers [32-34]. The patterning could also increase hysteresis by increasing sample's roughness, a very determinant parameter for hysteresis [30]. No EDS data has been collected because of the poor radiation resistance under the electron beam of this thin film (thickness e $=70 \mathrm{~nm}$ ).

On the whole samples, ageing in water affects integrity and cohesion of layers, by decreasing adhesion work by a factor of at least two. Parylene $\mathrm{C}$ coating adhesion is logically more robust than Fluorinated, taking into account that parylene is much thicker $(4.6-5.2 \mu \mathrm{m})$ and fluorinated polymer are deposited without coupling agent. The effect of such wearing, could also be shown by SEM coupled to EDS measurements to qualitatively correlate results.

In order to really understand ageing process and appearance of hysteresis, the origin of the degradation has to be identified. To investigate chemical ageing of the top surface, XPS and TOF-SIMS have been performed.

Fig. 6 presents negative mode ToF-SIMS spectra in the range of $\mathrm{m} / \mathrm{z}=15.4-17.2$ corresponding to $\mathrm{Oe}$ and $\mathrm{OHe}$ for a fresh and an aged Fluoropel sample. The Fluoropel is made of a fluoroacrylic polymer of general formula $n-\mathrm{C}_{22} \mathrm{H}_{14} \mathrm{O}_{4} \mathrm{~F}_{26}$. Fresh Fluoropel spectrum exhibits only the Oe peak, which is consistent with the presence of oxygen within the polymer. After ageing, the OHe peak (at $\mathrm{m} / \mathrm{z}=17$ ) is detected with a significant relative intensity. Even though it is not straightforward to link a single ToF-SIMS peak to a specific chemical function or group, it is possible in the current case to point that this signature indicates a surface modification consistent with $\mathrm{OH}$ terminated chemical functions. The spectrum is dominated by high intensity fluorocarbon signatures (easily detected in ToF-SIMS) but other differences are still identified in terms of hydrocarbon signatures (also more detected). No difference in terms of molecular 
high mass peaks was detected. From that point of view, it is unclear if the surface modification corresponds to a change in the chemical structure and/or to the detection at the surface of an oxygen containing hydrocarbon contribution. It must be reminded here that surface energy variation was not significant and this could be more consistent with the latter than with the former.
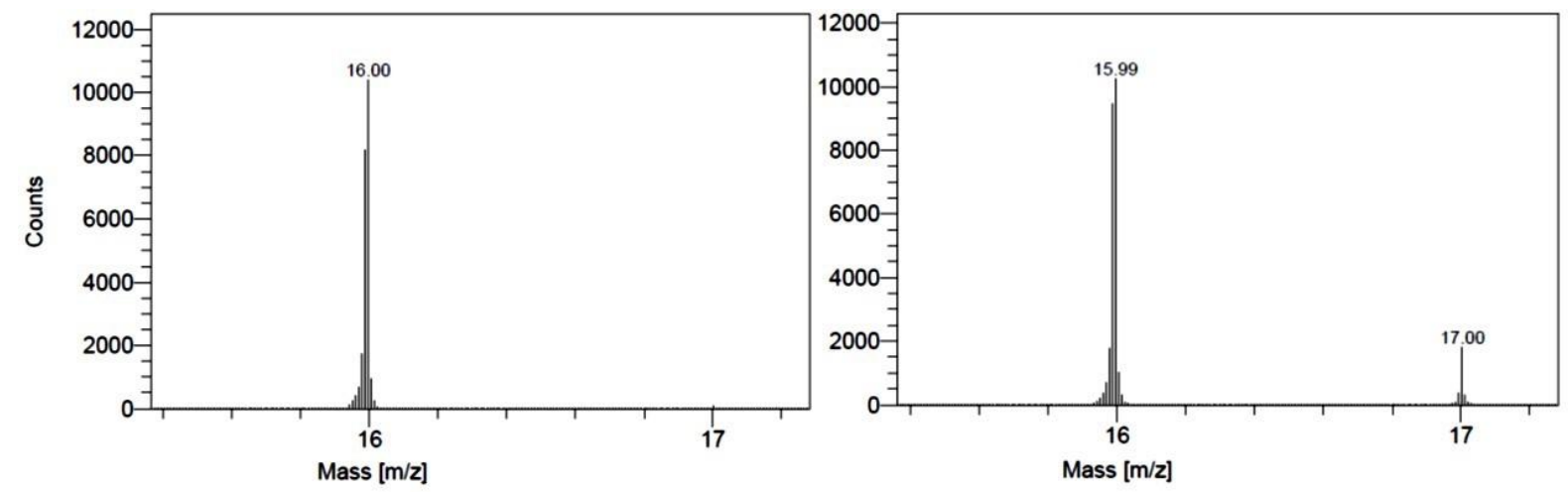

Figure 6 - Negative mode ToF-SIMS spectra of Fluoropel new (left) and aged (right) in the range of $\mathrm{m} / \mathrm{z}=$ 15.4-17.2

Fig. 7 describes negative mode ToF-SIMS spectra of Cytop layers before and after ageing in water. As described for Fluoropel, a peak appears around $17 \mathrm{~m} / \mathrm{z}$ on the weathered layer, exhibiting a possibly similar change at the top surface.
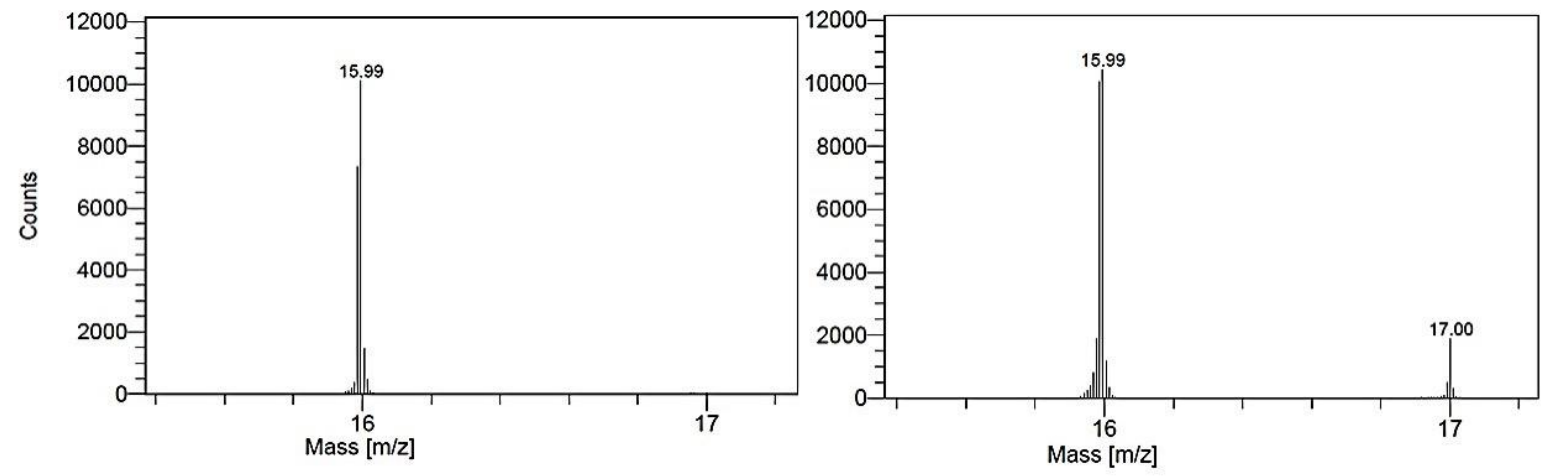

Figure 7 - Negative mode ToF-SIMS spectra of Cytop new (left) and aged (right) in the range of $\mathrm{m} / \mathrm{z}=$ 15.4-17.2

According to TOF-SIMS data, each of the layers were modified by ageing in water for one week at $85^{\circ} \mathrm{C}$, even those supposed to be insensitive to moisture and ageing such as fluoropolymers.

XPS analysis was also performed on Fluoropel in order to give a complementary view on the top layer surface chemical modification to those from ToF-SIMS and surface energy measurements.

Table 4 presents the atomic percentages and ratios for the main atoms composing Fluoropel coatings ( $\mathrm{Cl}$ was also slightly detected but its atomic percentage is not displayed in Table 4). As indicated above, it is based on the repetitive unit of formula $\mathrm{n}-\mathrm{C}_{22} \mathrm{H}_{14} \mathrm{O}_{4} \mathrm{~F}_{26}$. Oxygen and carbon atomic percentages increase from $\sim 12 \%$ to $\sim 17 \%$ and $\sim 35 \%$ to $\sim 45 \%$ respectively, while fluorine atomic percentage decreases from around $50 \%$ to $\sim 32 \%$. Fluorine was thus lost during the process of ageing, in favor of carbon and oxygen. One of the main hypothesis for this loss is the hydrolysis leading to the release of a very volatile compound known as $1 \mathrm{H}, 1 \mathrm{H}, 2 \mathrm{H}, 2 \mathrm{H}$-Perfluoro-1-octanol. This is displayed in Fig. 8 in the case of one of the two fluoro-alkyls but both could undergo this reaction. This hypothesis is based on the fact that oxygen in the ester group is the weak point of the polymer backbone, possibly undergoing reverse esterification in presence of water: $\mathrm{RCOOR}^{\prime}+\mathrm{H}_{2} \mathrm{O} \leftrightarrow \mathrm{RCOOH}+\mathrm{R}^{\prime} \mathrm{OH}$.

Table 4. XPS atomic percentages of $\mathrm{C}, \mathrm{O}$ and $\mathrm{F}$ for Fluoropel samples before and after ageing on two different locations on samples (point 1 and point 2) and comparison to theory calculation (see text for theory calculation after ageing). 


\begin{tabular}{llllll} 
& $\% \mathrm{C}$ & $\% \mathrm{~F}$ & $\% \mathrm{O}$ & $\mathrm{C} / \mathrm{F}$ & $\mathrm{O} / \mathrm{F}$ \\
\hline Fluoropel new pt 1 & 34.8 & 53 & 12 & 0.7 & 0.2 \\
Fluoropel new pt2 & 36.3 & 52 & 11.4 & 0.7 & 0.2 \\
Theory calculation before ageing & 42 & 50 & 8 & 0.8 & 0.15 \\
Fluoropel aged pt 1 & 42 & 32.9 & 18.2 & 1.3 & 0.6 \\
Fluoropel aged pt2 & 46.6 & 32 & 16 & 1.5 & 0.5 \\
Theory calculation after ageing & 48.5 & 32 & 19 & 1.5 & 0.6
\end{tabular}

XPS being based on atomic percentages, comparison of these percentages to the theoretical proposition from Fig. 8 may lead to the elucidation of the degradation mechanism. Before ageing, theory calculation values are based on the expected formula $n-\mathrm{C}_{22} \mathrm{H}_{14} \mathrm{O}_{4} \mathrm{~F}_{26}$ : each recurring unit contains 26 fluorine atoms, 22 carbon atoms and 4 oxygen atoms, for a total of 52 atoms that can be detected by XPS (thus excluding hydrogen atoms, not measured by XPS). It must be noted that the measured atomic percentages, even if falling in the expected range (especially for Fluorine), exhibit some differences (especially for 0) when compared to the Fluoropel composition (Chlorine traces is also an indication that surface is not in pristine condition).

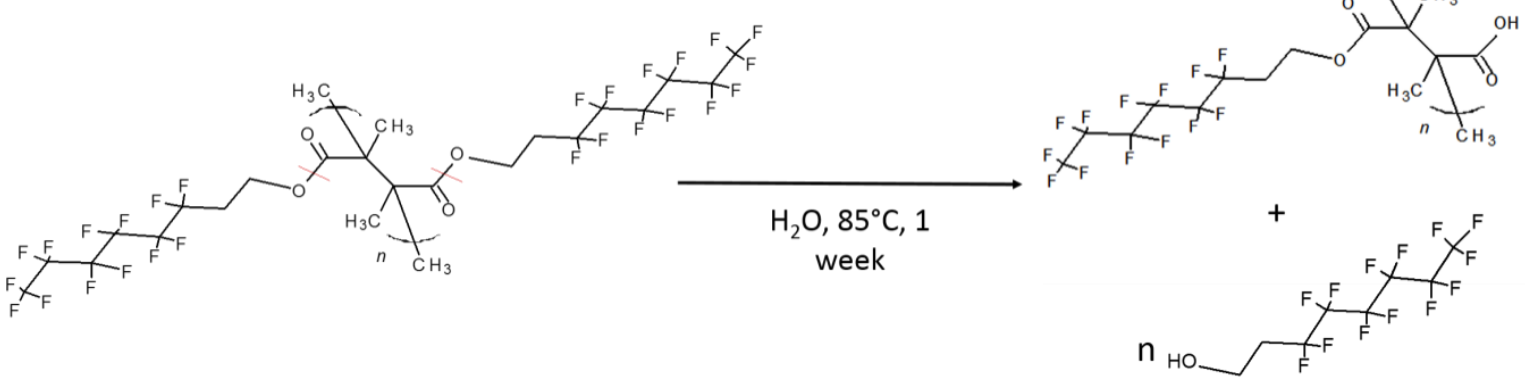

Figure 8 - Hydrolysis of Fluoropel leading to the release of a fluoro-alcohol<smiles>[R]C(F)C(F)(F)C(F)(F)C(F)(F)OC([R])(F)C(F)(F)F</smiles>

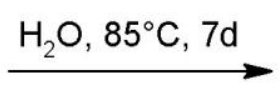<smiles>[R]C(C)C(F)(F)C(O)(C(F)(F)F)C(F)(F)C([R])(F)F</smiles>

Figure 9 - Hydrolysis of Cytop

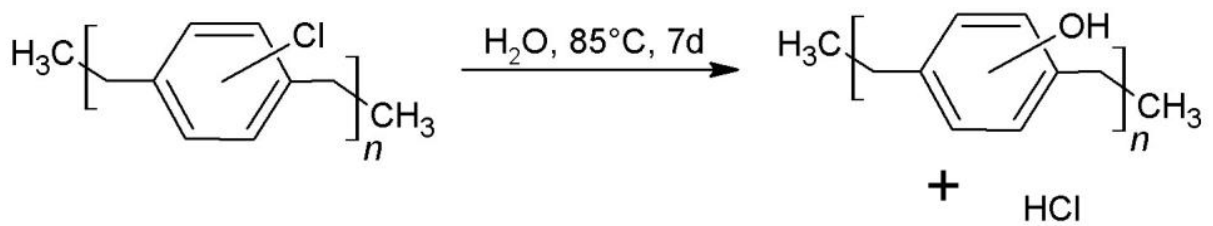

Figure 10 - Hydrolysis of Parylene $C$

Considering the case of fluorine, which is in the expected atomic percentage of $\sim 50 \%$ (26 fluorine /52 atoms) before ageing, a comparison with the remaining fluorine percentage of 32\% (see Table 4) after ageing makes possible to study the extent of side alcohol removed from the polymer per recurring unit. Considering $\mathrm{x}$ as the number of side alcohol released by hydrolysis per recurring unit ( $\mathrm{x}$ being comprised between 0 and 2), the fluorine content is given by: 


$$
=\% F=\frac{n_{F}}{n_{t o t}}=(2-x) \frac{n_{F}^{\text {init }}}{n_{\text {tot }}^{\text {init }}}=\frac{13(2-x)}{(13(2-x)+4+6+8(2-x)}=0,32 \Rightarrow x=\frac{9.36}{6.28}=1.49
$$

When considering loss of fluoro-alcohols, the total amount of atoms than remain unchanged is only given by the 4 oxygen atoms and the 6 carbon atoms behind the ester group. Therefore, 13 fluorine atoms and 8 carbon atoms per fluoro-alkyl part could be removed with the alcohol, they are thus included as (2-x) as maximum two alcohols released (xmax $=2$ ). The expected atomic content for carbon and oxygen are similarly calculated and in qualitative agreement with experimental data (see Table 4).

Hence the number of side alcohols removed from the polymer (1.49 entity) is higher than 1, i.e. at least one fluoro-alcohol is released per recurring unit. Hydrolysis of the ester group leaves a carboxylic acid function at the very top surface. However, about half the flexible fluoroalkyl chains remain on one side, potentially covering the potential carboxylic acid groups: no changes are visible using surface energy measurements and a spectrum dominated by fluorocarbon peaks of the ToF-SIMS analysis (even more top-surface sensitive than XPS). For the latter, $\mathrm{OH}$ terminated chemical groups were still detected, giving a first indication of this surface modification. These results correlate with TOF-SIMS measurements in which $\mathrm{OH}$ terminated chemical groups were detected.

Hydrolysis reaction hypotheses can also be made for the two other layers:

- Cytop undergoes ring opening. (Fluorine create tension in the molecule by strongly polarizing the CeF bond), weakening the carbon oxygen bond by electron's delocalization) (Fig. 9).

- Parylene C chlorine is hydrolyzed, and, forming an hydroxyl group [35] on the aromatic ring (Fig. 10).

\section{Conclusion}

Characterizing layers used in electro-wetting is the key to obtain reliable devices. Each coating reacts in a different way to ageing, even though final result is somehow similar, with apparition of a wetting hysteresis. Parylene $\mathrm{C}$ when aged in water at $85^{\circ} \mathrm{C}$, exhibits the largest modifications in term of surface energy and thus in term of wetting whereas layer cohesion is only slightly modified by weathering. Cytop surface energy is less modified by ageing than parylene C. However, top surface analysis demonstrated that the coating is chemically modified, creating anchor point and thus hysteresis. Finally, there is no significant modification of Fluoropel surface energy but TOF-SIMS analysis still exhibits hydroxyl group on the top surface whereas XPS points out hydrolysis of a lateral chain. No noticeable modification is observed on surface energy polar part: since lateral chains are mobile, hydroxyl groups can be eventually covered and layer behaves as if non-aged. Chemical ageing is not easily overpassed. It needs modifying directly the chemical structure of the coating, for example using the method presented by Glaris et al. [36], grafting fluorinated chain directly on the coating. Physical ageing (such as de-cohesion, dwelling ...) can be easily improved by adding charge or anti-oxidant products directly to the coating solution. Adhesion can be promoted by adhesion agent, as shown by Hegemann et al. [37], or by depositing an anchor coating, shown by Papathanasiou et al. [38].

These results demonstrate that wetting hysteresis from hydrophobic coating used in electrowetting applications originate from various parameters, and a relevant failure analysis requires in some case advanced analytical measurements such as TOF-SIMS and XPS.

Now, tests performed on materials must be easy, reproducible and quantitative in order to make them applicable to industrial standard. Based on our analysis, tests could be divided in two types: routine and advanced reliability tests. Each coating is required to go through routine reliability test (such as here, electrowetting, surface energy or adhesion) before considering more advanced analysis. Our results demonstrate a cost effective failure analysis methodology, applicable to coatings industrial batches as well as newly designed hydrophobic coatings used electrowetting based actuator and applications involving hydrophobic coatings.

\section{Acknowledgement}

We would like to thank Science \& Surface from Lyon for the providing of XPS analysis on our samples, their quick answer and their expertise. 
This work was supported by the Association Nationale Recherche Technologie within the program "Conventions Industrielles de Formation par la Recherche" $N^{\circ} 2014 / 0506$ and by the business unit Varioptic.

\section{References}

[1] J.D. Venables, Adhesion and durability of metal-polymer bonds, J. Mater. Sci. 19 (1984) 2431-2453, http://dx.doi.org/10.1007/BF00550796.

[2] R. Comrie, S. Affrossman, D. Hayward, R.A. Pethrick, X. Zhou, G.E. Thompson, Study of ageing of adhesive bonds with various surface treatments: Part VI. Dicyandiamide-cured epoxy joints aged at $70{ }^{\circ} \mathrm{C}$ in a water bath, J. Adhes. Sci. Technol. 20 (2006) 1847-1872, http://dx.doi.org/10.1163/ 156856106779116597.

[3] C.F. Korenberg, A.J. Kinloch, J.F. Watts, Crack growth of structural adhesive joints in humid environments, J. Adhes. 80 (2004) 169-201, http://dx.doi.org/10.1080/ 00218460490279233.

[4] K.S. Gadre, T.L. Alford, Contact angle measurements for adhesion energy evaluation of silver and copper films on parylene-n and SiO2 substrates, J. Appl. Phys. 93 (2002) 919-923, http://dx.doi.org/10.1063/1.1530362.

[5] R.A. Dickie, Paint adhesion, corrosion protection, and interfacial chemistry, Prog. Org. Coat. 25 (1994) 3-22, http://dx.doi.org/10.1016/0300-9440(94)00500-1.

[6] D.L. Cho, K.H. Shin, W.-J. Lee, D.-H. Kim, Improvement of paint adhesion to a polypropylene bumper by plasma treatment, J. Adhes. Sci. Technol. 15 (2001) 653-664, http://dx.doi.org/10.1163/156856101750430404.

[7] I. Sutherland, D.M. Brewis, R.J. Health, E. Sheng, Modification of polypropylene surfaces by flame treatment, Surf. Interface Anal. 17 (1991) 507-510, http://dx.doi. org/10.1002/sia.740170717.

[8] F. Garbassi, E. Occhiello, F. Polato, A. Brown, Surface effect of flame treatments on polypropylene, J. Mater. Sci. 22 (1987) 1450-1456, http://dx.doi.org/10.1007/ BF01233147.

[9] R. Shamai, D. Andelman, B. Berge, R. Hayes, Water, electricity, and between ... on electrowetting and its applications, Soft Matter 4 (2007) 38-45, http://dx.doi.org/ 10.1039/B714994H.

[10] R.B. Fair, Digital microfluidics: is a true lab-on-a-chip possible? Microfluid. Nanofluid. 3 (2007) 245281, http://dx.doi.org/10.1007/s10404-007-0161-8.

[11] V.N. Luk, A.R. Wheeler, A digital microfluidic approach to proteomic sample processing, Anal. Chem. 81 (2009) 4524-4530, http://dx.doi.org/10.1021/ac900522a.

[12] A. Rival, D. Jary, C. Delattre, Y. Fouillet, G. Castellan, A. Bellemin-Comte, X. Gidrol, An EWOD-based microfluidic chip for single-cell isolation, mRNA purification and subsequent multiplex qPCR, Lab Chip 14 (2014) 3739-3749, http://dx.doi.org/10. 1039/C4LC00592A.

[13] J. Heikenfeld, K. Zhou, E. Kreit, B. Raj, S. Yang, B. Sun, A. Milarcik, L. Clapp, R. Schwartz, Electrofluidic displays using Young-Laplace transposition of brilliant pigment dispersions, Nat. Photonics 3 (2009) 292296, http://dx.doi.org/10.1038/ nphoton.2009.68.

[14] B. Berge, J. Peseux, Variable focal lens controlled by an external voltage: an application of electrowetting, Eur. Phys. J. E. 3 (2000) 159-163, http://dx.doi.org/10. 1007/s101890070029.

[15] B.H.W. Hendriks, S. Kuiper, M.A.J.V. As, C.A. Renders, T.W. Tukker, Electrowetting-based variablefocus lens for miniature systems, Opt. Rev. 12 (2005) 255-259, http://dx.doi.org/10.1007/s10043-0050255-Z.

[16] M. Dhindsa, J. Heikenfeld, W. Weekamp, S. Kuiper, Electrowetting without electrolysis on self-healing dielectrics, Langmuir 27 (2011) 5665-5670, http://dx.doi. org/10.1021/la1051468.

[17] R. Gupta, D.M. Sheth, T.K. Boone, A.B. Sevilla, J. Fréchette, Impact of pinning of the triple contact line on electrowetting performance, Langmuir $27 \quad$ (2011) 14923-14929, http://dx.doi.org/10.1021/la203320g.

[18] J.B. Chae, J.O. Kwon, J.S. Yang, D. Kim, K. Rhee, S.K. Chung, Optimum thickness of hydrophobic layer for operating voltage reduction in EWOD systems, Sensors Actuators A Phys. 215 (2014) 8-16, http://dx.doi.org/10.1016/i.sna.2013.11.001.

[19] NF EN 60068-2-2 - "Essais d'environnement - Partie 2-2: essais - Essais B : chaleur sèche".

[20] G. Bonfante, S. Chevalliot, B. Toury, B. Berge, M. Maillard, Two-liquid wetting properties as a surface polarity probe for hydrophobic coatings, Phys. Chem. Chem. Phys. 19 (2017) 3214-3218, http://dx.doi.org/10.1039/C6CP07392A.

[21] M.N. Bellon-Fontaine, N. Mozes, H.C. van der Mei, J. Sjollema, O. Cerf, P.G. Rouxhet, H.J. Busscher, A comparison of thermodynamic approaches to predict the adhesion of dairy microorganisms to solid substrata, Cell Biophys. 17 (1990) 93-106. 
[22] J.J. Jasper, The surface tension of pure liquid compounds, J. Phys. Chem. Ref. Data 1 (1972) 841-1010, http://dx.doi.org/10.1063/1.3253106.

[23] H.J. Busscher, A.W.J. van Pelt, P. de Boer, H.P. de Jong, J. Arends, The effect of surface roughening of polymers on measured contact angles of liquids, Colloids Surf. A Physicochem. Eng. Asp. 9 (1984) 319-331, http://dx.doi.org/10.1016/ 0166-6622(84)80175-4.

[24] C. Jie-Rong, T. Wakida, Studies on the surface free energy and surface structure of PTFE film treated with low temperature plasma, J. Appl. Polym. Sci. 63 (1997) 1733-1739, http://dx.doi.org/10.1002/(SICI)1097-4628(19970328) 63:13<1733::AID-APP4>3.0.CO;2-H.

[25] B. Jańczuk, T. Białlopiotrowicz, Surface free-energy components of liquids and low energy solids and contact angles, J. Colloid Interface Sci. 127 (1989) 189-204, http://dx.doi.org/10.1016/00219797(89)90019-2.

[26] J. Jakabovič, J. Kováč, M. Weis, D. Haško, R. Srnánek, P. Valent, R. Resel, Preparation and properties of thin parylene layers as the gate dielectrics for organic field effect transistors, Microelectron. J. 40 (2009) 595-597, http://dx.doi.org/10.1016/j.mejo.2008.06.029.

[27] R. Daviau, A. Khan, E. Lisicka-Skrzek, R.N. Tait, P. Berini, Fabrication of surface plasmon waveguides and integrated components on Cytop, Microelectron. Eng. 87 (2010) 1914-1921, http://dx.doi.org/10.1016/j.mee.2009.11.078.

[28] B. Berge, Électrocapillarité et mouillage de films isolants par l'eau, C. R. Acad. Sci. Paris. 317 (1993) 157-163.

[29] L. Gao, T.J. McCarthy, Contact angle hysteresis explained, Langmuir 22 (2006) 6234-6237, http://dx.doi.org/10.1021/la060254j.

[30] D. Öner, T.J. McCarthy, Ultrahydrophobic surfaces. effects of topography length scales on wettability, Langmuir 16 (2000) 7777-7782, http://dx.doi.org/10.1021/ la000598o.

[31] M. Maillard, J. Legrand, B. Berge, Two liquids wetting and low hysteresis electrowetting on dielectric applications, Langmuir 25 (2009) 6162-6167, http://dx.doi. org/10.1021/la804118y.

[32] G.C. Sih, Fracture mechanics of adhesive joints, Polym. Eng. Sci. 20 (1980) 977-981, http://dx.doi.org/10.1002/pen.760201410.

[33] M.D. Banea, L.F.M. da Silva, Mechanical characterization of flexible adhesives, J. Adhes. 85 (2009) 261-285, http://dx.doi.org/10.1080/00218460902881808.

[34] M.R. Bowditch, The durability of adhesive joints in the presence of water, Int. J. Adhes. Adhes. 16 (1996) 73-79, http://dx.doi.org/10.1016/0143-7496(96) 00001-2.

[35] J.F. Bunnett, R.E. Zahler, Aromatic nucleophilic substitution reactions, Chem. Rev. 49 (1951) 273-412, http://dx.doi.org/10.1021/cr60153a002.

[36] P. Glaris, J.-F. Coulon, M. Dorget, F. Poncin-Epaillard, N2 plasma-assisted grafting of fluorinated chains onto partially cured epoxy resins, Compos. Part B Eng. 69 (2015) 6-12, http://dx.doi.org/10.1016/j.compositesb.2014.09.019.

[37] D. Hegemann, H. Brunner, C. Oehr, Plasma treatment of polymers for surface and adhesion improvement, Nucl. Instrum. Methods Phys. Res. Sect. B Beam Interact. Mater. At. 208 (2003) 281-286, http://dx.doi.org/10.1016/S0168-583X(03) 00644-X.

[38] D.P. Papageorgiou, A. Tserepi, A.G. Boudouvis, A.G. Papathanasiou, Superior performance of multilayered fluoropolymer films in low voltage electrowetting, J. Colloid Interface Sci. 368 (2012) 592598, http://dx.doi.org/10.1016/j.jcis.2011. 10.035. 